\title{
Methodological Approaches to the Assessing of the Quality of Audit Sampling
}

\author{
Meleshenko S.S.
}

Kazan Federal University, Institute of Management, Economics and Finance, Kazan, 420008, Russia

Email address: dek_fep@mail.ru

Usanova D.S.

Kazan Federal University, Institute of Management, Economics and Finance, Kazan, 420008, Russia

\section{Doi:10.5901/mjss.2014.v5n24p176}

\begin{abstract}
The main objective of this study is to develop methodology of assessing the quality of the audit sampling. The use of the sampling leads to existence of the risks when an auditor's conclusion, made on the basis of a total sample may be different from the conclusion drawn on the basis of the audit procedures carried out in respect of all population elements. To solve this problem we have created the theoretical model, illustrating the following: the relationship between the audit risk and the methods of the unit's selection; the relationship between the efficiency of the audit, evaluation of internal control and audit scope; the use of sampling in the audit for internal control testing and substantive procedures.
\end{abstract}

Keywords: audit, standard, sampling, quality of audit, risk, ISA

\section{Introduction}

The problem of sampling and obtaining appropriate audit evidence discussed in scientific articles at the eighties of the twentieth century. In those years focus was on the development of common fixed standard approaches [1] that would create a methodological framework to develop an audit technology.

A globalization of business, and as a consequence, the occurrence of large volumes of financial data, led to the problem of studying a huge number of audit evidences sources. In the 90 -ies of XX century several research studies were devoted to the use of sampling techniques in auditing [2], [3]. The main trend of these studies was the adaptation of the sampling methods used, mainly, in microeconomics. A little later, several researchers have been investigated the problem of the quality of audit sampling [4], [5], including a problem of heterogeneity of sampling.

In 2002 the Sarbanes-Oxley Act (Sarbanes-Oxley Act, SOX) was adopted. In accordance with the SOX for open joint stock companies a new regime for the control and regulation of financial activities was created. And there were significant changes in the management and disclosure requirements. Requirements for auditors have become more stringent: the need to coordinate their actions with the Audit Committee, including the main provisions of accounting to be used in the audit, various options for assessing the financial information under GAAP. These requirements, ultimately, focus an attention on the problem of the quality of audit services. So at the beginning of the XXI century it have become popular to study a linking of this stringent measures [6], [8], [9], [10], written in Sarbanes-Oxley Act, with a quality of auditing. However, in such studies the problem of quality of individual technologies used in the auditing was not widely discussed.

Until now questions of the qualitative sampling, as one of the most important procedures during the audit are remaining unsolved. In the following studies $[11,12,13]$ the individual methods of audit sampling, described their advantages and disadvantages and applicability in different situations are examined. Nevertheless, it is necessary not only to investigate directly sampling methods used in the auditing, but also to develop the methodological aspects of quality assessment conducted to sampling procedures, that also are relevant for the quality control of audit services.

\section{Audit Sampling}

The essence of selective audit procedures is that the less of $100 \%$ elements of financial data would be examined by an auditor. The main reason to use a selective approach is the high amount of time to carry out continuous testing and the high cost of audit services. Basic principles of the audit sampling are reflected in the International Standard on Auditing 
(ISA) 530, "Audit Sampling".

The terms "standard", "rule" are applied to information sources that contain requirements to specific conditions to achieve a certain goal. So auditing standards should include a description of such procedures, the implementation of which would achieve the main goal - qualitative audit.

Consider from this point of view, an important technological aspect of the audit - a selective approach to the study of verifiable information.

According to the ISA 530 Audit sampling - The application of audit procedures to less than $100 \%$ of items within a population of audit relevance such that all sampling units have a chance of selection in order to provide the auditor with a reasonable basis on which to draw conclusions about the entire population.

It is clear, that continuous verification of documents is not an audit sampling. Moreover, the selection of specific (certain) elements as a method of selection is not an audit sampling. This means that the implementation of audit sampling takes place only in the case of the selection of the individual (specific) items for testing. From this it follows that for a continuous screening and selection of specific elements of the accounting, aspects of risk assessment and audit evidence obtaining must treat separately, given, that the basis of this approach to the selection of elements is the professional judgment of the auditor.

\section{Methods}

The use of sampling leads to the existence of the risks when auditor's conclusion, made on the basis of the total sample may be different from the conclusion drawn on the basis of the audit procedures carried out in respect of all elements of the population.

Based on the practical experience of the audit, the authors using scientific methods such as analysis and synthesis developed a theoretical model which reflects relationship between: the audit risk and the methods of the unit's selection; the efficiency of the audit, evaluation of internal control and audit scope. The main result of sampling use in the audit (internal control testing and substantive procedures) we summarized in a form of table.

\section{Results and Conclusions}

The relationship between the audit risk and the methods of the unit's selection is shown in the Table 1.

Table 1. The relationship between the audit risk and the methods of the units sampling

\begin{tabular}{|l|c|c|c|}
\hline \multirow{2}{*}{ Information about risks } & \multicolumn{3}{|c|}{ Units sampling methods } \\
\cline { 2 - 4 } & All units sampling & Specific units sampling & $\begin{array}{c}\text { Separate units sampling } \\
\text { (audit sampling) }\end{array}$ \\
\hline Risks not associated with the use of audit sampling & yes & yes & no \\
\hline Risks associated with the use of audit sampling & no & no & yes \\
\hline Audit procedures to reduce the risk & $\begin{array}{l}\text { - proper planning tasks, } \\
\text { - monitoring of the auditors work, } \\
\text { - verification of compliance the procedures. }\end{array}$ & Increase a sample size \\
\hline
\end{tabular}

Reducing the risk procedures depend on the method of units sampling. As can be seen from the Table 1, reducing the risk in the audit sample is more specific, while continuous check and selection of specific units suggest the implementation of procedures of quality content. This required level is provided by the auditors in dependence on the structure and management system of the audit firm and, ultimately, based on the auditor's judgment. Procedures designed to reduce the impact of this judgment may be based on two principles: the periodicity of monitoring and documenting of the work of auditors.

Control technique involves the verification of the audit procedures. Thus, it is more logical to designate only two procedures, proper planning and monitoring of auditors work. In modern conditions fixation the formation of the audit sampling in the working papers depends on the automation level of the audit process. Audit programs involve selection of units in a given mode. It allows controlling the sampling procedures. Partial automation of the audit process is more timeconsuming to generate documentation. It is necessary to clarify, that in this case it is a requirement of reflection of selection methods used by the auditor in the working papers, and not the result set.

Thus, the method of selecting the items in the sampling frame has an impact not only on the audit procedures to 
reduce the risk, but also on the quality control procedures of the audit. Selection of separate units requires less control procedures than other methods of selection. In addition, detailed documentation of quality control can be formed in parallel with the sampling procedures. For the other two methods of forming a sample the number of control procedures and, consequently, the working documentation increases.

The risk associated with the use of a sampling depends on the content of the general population. If it is a substantive test, the risk of sample leads to the increasing in the detection risk. If the sampling approach is applied to the testing of internal controls, the effect of the risk associated with the use of sampling is greatly enhanced. The occurrence of these risks is due to the incorrect evaluation of the efficiency level of internal controls. The relationship between risk of using sampling in evaluating the efficiency of internal controls (the ICS - internal control system) and the scope of audit is presented in Figure 1.

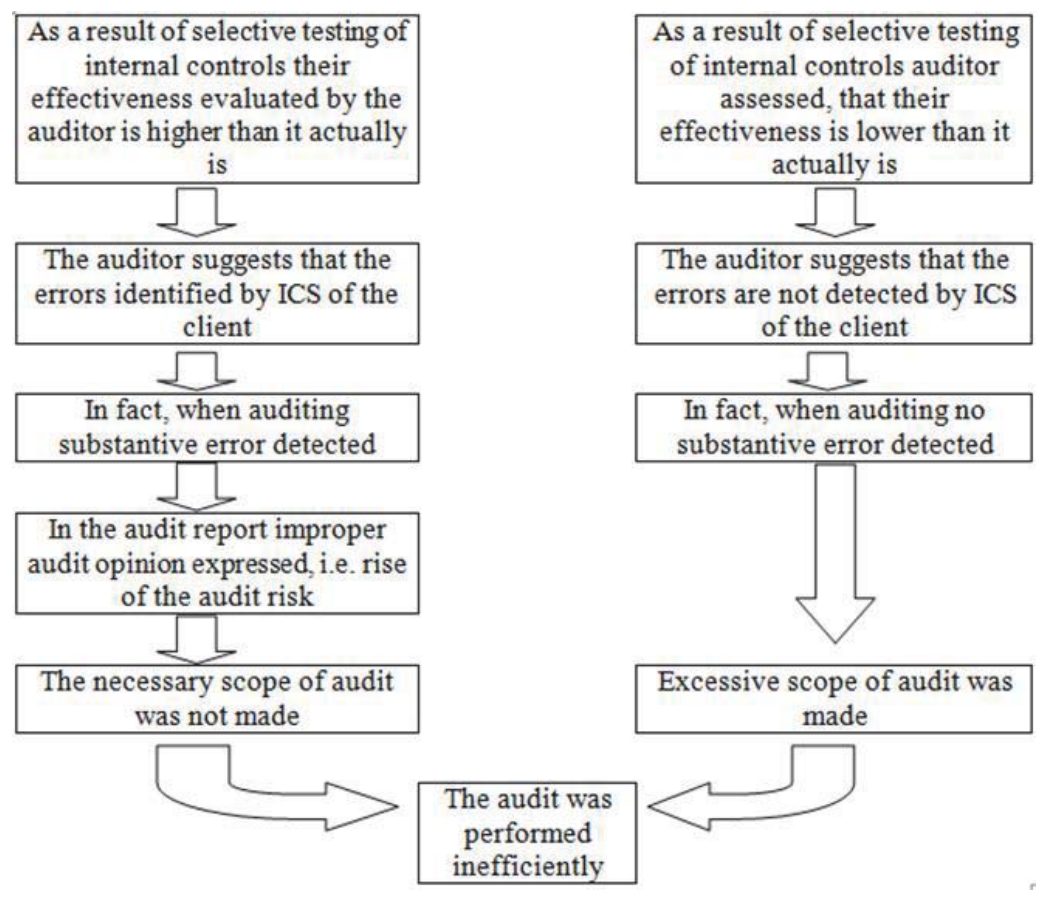

Fig. 1 The relationship between the efficiency of the audit, evaluation of internal control and audit scope.

The efficiency of the audit - is an important problem. Audit as entrepreneurial activity is characterized by all its inherent problems, including an adequate evaluation. Figure 1 shows one of the indicators for this evaluation: audit scope (extent of audit procedures). During the audit, this means the optimum combination of the scope of procedures with a confidence level of auditor in the reliability of financial reporting.

The complexity of the formation of such a measure is to combine quantitative (in scope) and quality (confidence level) components inspection. Audit activity is usually indicated in the required scope of procedures to ensure the appropriate level of confidence, which ultimately rests on the professional judgment of the auditor. The solution to this problem may lie in the replacement of this judgment with deterministic communication considered indicators. The tougher is this relationship, the more appropriate can be estimated an auditors work.

Internal control testing is a crucial component of external auditing. Aspects of the sample are considered to check internal controls and operations in order to identify common and distinct sides. This will determine the procedures to obtain audit evidences, which can then be quantified and ultimately uniquely evaluated in order to determine the quality of auditing.

General population can be either a set of operations, documents, etc., studied at check essentially or a set of internal control tools. This affects the methodology of audit sampling, assessment of its risk and results. Application sampling to internal control testing and substantive procedures in the audit is given in the Table 2. 
Table 2. The use of sampling in the audit: internal control testing and substantive procedures

\begin{tabular}{|l|l|l|}
\hline \multirow{2}{*}{ Aspect } & \multicolumn{2}{|c|}{ The use of sampling } \\
\cline { 2 - 3 } & to ICS & to substantive procedures \\
\hline Obtaining audit evidence & $\begin{array}{l}\text { Sampling is appropriate if } \\
\text { there is evidence of ICS }\end{array}$ & $\begin{array}{l}\text { The sample used in the preparation of proofs of the } \\
\text { correctness of one or more prerequisites reporting or } \\
\text { evaluation index }\end{array}$ \\
\hline $\begin{array}{l}\text { The risk associated with the use of } \\
\text { sampling }\end{array}$ & $\begin{array}{l}\text { Evaluation ICS at a lower } \\
\text { level than is actually }\end{array}$ & Undetected errors in the selected set of \\
\hline $\begin{array}{l}\text { Procedures to mitigate the risk } \\
\text { associated with the use of sampling }\end{array}$ & \multicolumn{2}{|c|}{ Increase in sampling size } \\
\hline $\begin{array}{l}\text { Risk that is not associated with the use } \\
\text { of sampling }\end{array}$ & \begin{tabular}{l} 
The of inadequate audit procedures \\
\hline $\begin{array}{l}\text { Procedures to reduce the risk that is not } \\
\text { associated with the use of sampling }\end{array}$
\end{tabular} & $\begin{array}{l}\text { Proper planning tasks } \\
\text { Routine inspection of the auditors } \\
\text { To verify compliance with procedures }\end{array}$ \\
\hline $\begin{array}{l}\text { Consequence of the unexpectedly high } \\
\text { error rate in the selected set of }\end{array}$ & $\begin{array}{l}\text { The probability of increasing } \\
\text { the level of risk of ICS }\end{array}$ & \multicolumn{1}{|c|}{ Significant misrepresentation of item } \\
\hline Audit procedures to reduce audit risk & \multicolumn{2}{|c|}{ Obtain additional audit evidence substantiating the initial lower share of mistakes } \\
\hline
\end{tabular}

Thus, the consideration of certain aspects of audit sampling in the context of assessing the quality of the audit revealed the need to develop methods for determining the quality of audit services based on quantitative criteria and indicators.

\section{References}

William R. Kinney Jr. (1986). Audit technology and preferences for auditing standards, Journal of Accounting and Economics, Volume 8, Issue 1, March, pp. 73-89.

Brian Carpenter (1993). Sampling and the abstraction of knowledge in the auditing profession: An extended institutional theory perspective, Accounting, Organizations and Society, Volume 18, Issue 1, January, pp. 41-63.

Doganaksoy, Necip; Hahn, Gerald J. (1994). Moving From Every-Lot Inspection to Audit Sampling, Journal of Quality Technology Vol. 26 No. 4, QICID: 11389 October, pp. 261-273.

Pierre Gy (1998). Sampling for Analytical Purposes, Hardcover, March, ISBN: 978-0-471-97956-2

Patricia L. Smith (2004). Audit and assessment of sampling systems, Chemometrics and Intelligent Laboratory Systems, Volume 74, Issue 1, 28 November, pp. 225-230.

Mark L. DeFond, Clive S. Lennox (2011). The effect of SOX on small auditor exits and audit quality, Journal of Accounting and Economics, Volume 52, Issue 1, June 2011, pp. 21-40.

Kharisova F.I. and Rakhmanova I.I. (2014). Sampling in Tax Audit. World Applied Sciences Journal 31 (1): pp. 138-142.

Ellen Engel, Rachel M. Hayes, Xue Wang (2010). Audit committee compensation and the demand for monitoring of the financial reporting process, Journal of Accounting and Economics, Volume 49, Issues 1-2, February, pp. 136-154.

Hollis Ashbaugh-Skaife, Daniel W. Collins, William R. Kinney Jr. (2007). The discovery and reporting of internal control deficiencies prior to SOX-mandated audits, Journal of Accounting and Economics, Volume 44, Issues 1-2, September, pp. 166-192.

Mohamed Hegazy, Noha Abou Kamer (2010). A critical analysis of auditors' perception of the impact of Section 404 of the Sarbanes Oxley Act on audit quality: an Egyptian perspective, Afro-Asian J. of Finance and Accounting, Vol. 2, No.2 pp. 154 - 182.

Huong N. Higgins, Balgobin Nandram (2009). Monetary unit sampling: Improving estimation of the total audit error, Advances in Accounting, Volume 25, Issue 2, December, pp. 174-182.

Khismatullin B.R. and Kharisova F.I. (2014). Insurance as a Way for Reducing the Market Risks Level. World Applied Sciences Journal 31 (6): pp. 1188-1190.

Trevor R. Stewart (2008). Technical Notes on the AICPA Audit Guide Audit Sampling, American Institute of Certified Public Accountants, Inc. New York, NY 10036-8775.

Conor O'Leary, Errol Iselin, Divesh Sharma (2006). Audit firm manuals and audit experts' approaches to internal control evaluation, Int. J. of Accounting, Auditing and Performance Evaluation, Vol. 3, No.1 pp. 20 - 40. 